Jaqueline Gomes

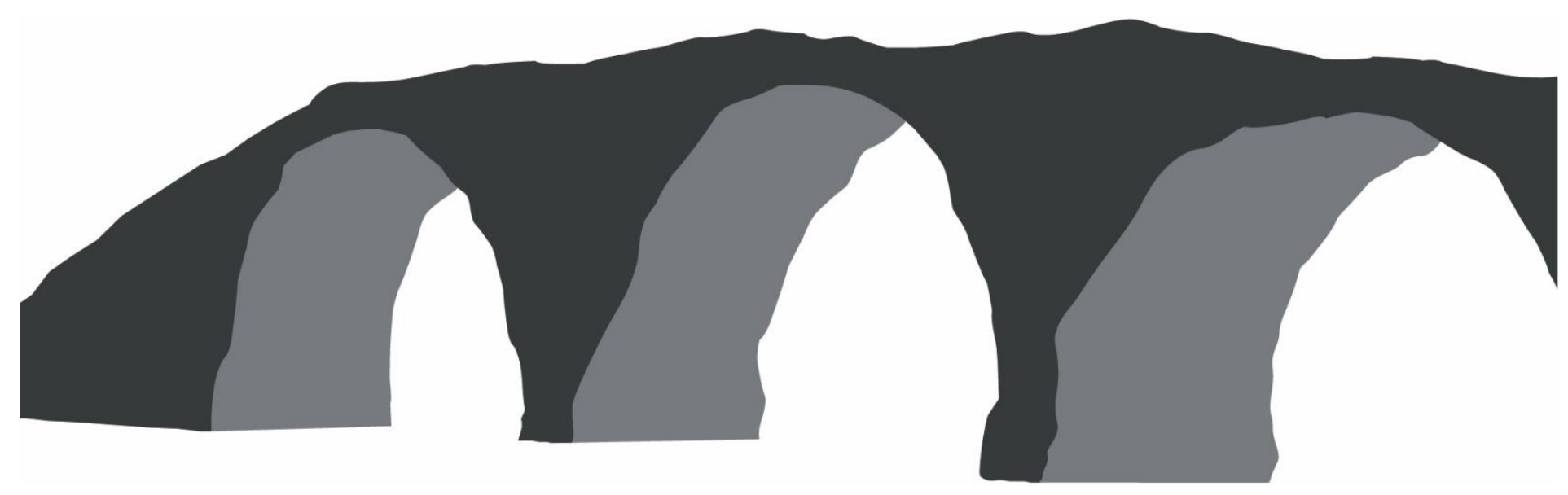




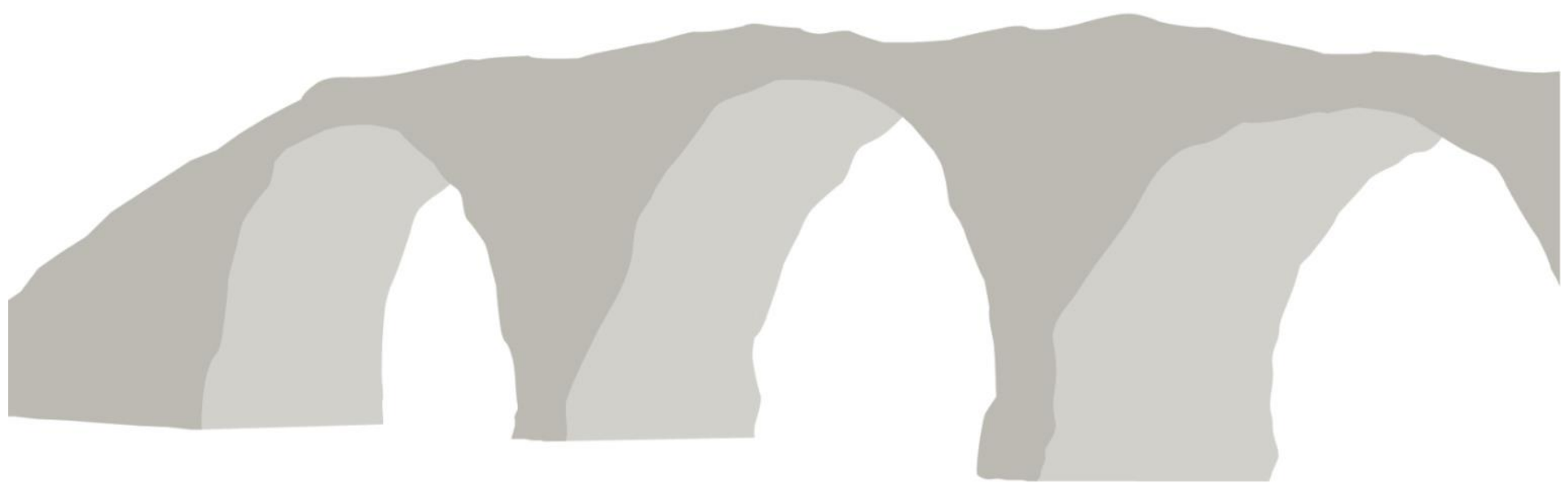

Data de recebimento: 06/10/2018.

Data de aceite: 19/11/2018. 


\title{
UMA PERSPECTIVA ONTOLÓGICA PARA UMA ANÁLISE ETNOARQUEOLÓGICA DAS PAISAGENS DO LAGO AMANÃ, BAIXO JAPURÁ, AMAZONAS
}

\section{AN ONTOLOGICAL PERSPECTIVE FOR AN ETNOARCHAEOLOGICAL ANALYSIS OF THE LANDSCAPES OF AMANÃ LAKE, JAPURÁ LOWER RIVER, AMAZONAS}

\author{
Jaqueline Gomes ${ }^{1}$
}

\begin{abstract}
RESUMO
Neste texto procuro explorar desdobramentos de uma pesquisa etnoarqueológica focada nas formas de transformação e significação das paisagens locais entre comunidades ribeirinhas de uma unidade de conservação do interflúvio dos rios Japurá e Negro, no Estado do Amazonas. Arqueólogos, quando se ocupam de estudos sobre as paisagens, procuram por marcas antrópicas. Entre os ribeirinhos de Amanã, diversos seres além dos humanos deixam suas marcas nas paisagens, que reverberam nos processos de formação dos territórios contemporâneos. A existência de seres não-humanos, os encantados, que habitam a mata e o próprio lago, e agem conscientemente, faz parte do repertório para explicar estratégias de uso de recursos e dinâmicas da ocupação humana. O exercício proposto é considerar outras ontologias como ponto de partida para entender as formas locais de engajamento com a paisagem contemporânea e arqueológica.

Palavras-chave: Populações Ribeirinhas, Ontologia Ameríndia, Etnoarqueologia Amazônica.
\end{abstract}

\section{RESUMEN}

En este texto objetivo explotar desdoblamientos de una investigación etnoarqueológica enfocada en las formas de transformación y significación de los paisajes locales entre comunidades ribereñas de una unidad de conservación del interfluvio de los ríos Japurá y Negro, en el Estado de Amazonas. Arqueólogos cuando se ocupan de estudios sobre los paisajes buscan marcas antrópicas. Entre los ribereños de Amanã, diversos seres más allá de los humanos dejan sus huellas en los paisajes, que reverberan en los procesos de formación de los territorios contemporáneos. La existencia de seres no humanos, los encantados, que habitan la selva y el propio lago, y actúan conscientemente, formam parte del repertorio para explicar estrategias de uso de recursos y dinámicas de la ocupación humana. El ejercicio propuesto es considerar otras ontologías como punto de partida para entender las formas locales de compromiso con el paisaje contemporáneo y arqueológico.

Palabras clave: Poblaciones Ribereñas, Ontología Amerindia, Etnoarqueología Amazónica.

\footnotetext{
${ }^{1}$ Doutoranda do Programa de Pós-Graduação em Antropologia da Universidade Federal de Minas Gerais. Mestre em Arqueologia pelo Museu de Arqueologia e Etnologia da Universidade de São Paulo. E-mail: jaquelinegomes06@gmail.com.
} 


\section{ABSTRACT}

In this text I try to explore developments in an ethnoarchaeological research focused on the forms of transformation and signification of the local landscapes in riverside communities of a protected area of the Japurá and Negro rivers interflowing in the State of Amazonas. Archaeologists when dealing with landscape studies look for anthropic marks. Amongst the riverines of Amanã, beings other than humans leave their mark on the landscape, which reverberates in the processes of formation of contemporary territories. The existence of nonhuman beings, the enchanted, who inhabit the forest and the lake itself, and act consciously, is part of the repertoire to explain strategies for the use of resources and the dynamics of human occupation. The proposed exercise is to consider other ontologies as a starting point to understand the local forms of engagement with the contemporary and archaeological landscape.

Keywords: Riverside Populations, Amerindian Ontology, Ethnoarchaeology. 


\section{INTRODUÇÃO}

Há 7 anos, em um fim de tarde, eu seguia no barco com mais um grupo de companheiros e pesquisadores para o Amanã, um lago imenso de águas pretas, que dá nome a uma unidade de conservação de uso sustentável, localizada no interior do estado do Amazonas. Havia entre nós assistentes de campo, nascidos à beira daquele lago, moradores de comunidades que trabalharíamos e conhecedores experientes daquele lugar. Conversava com um deles, já um grande amigo naquela ocasião, e planejávamos os nossos momentos de lazer no decorrer da etapa de campo, com certeza entre eles estariam os banhos no lago. Em meio à conversa, eu reafirmo que não sabia nadar. Ao que ele me responde: Mas, Jaque, fica tranquila, vou te mostrar, só não pode ir onde é perigoso, nem ir com os arigós ${ }^{2}$, porque eles que não sabem onde é casa da cobra grande!

Posteriormente, fui levada ao lugar onde seria a casa da cobra grande naquele mundo subaquático. Para minha surpresa, estava diretamente relacionado à ausência de comunidades atuais às margens do lago. Tempos depois, percebi que ali também, até o momento, é um vazio arqueológico sem identificação de vestígios materiais de usos em períodos anteriores.

Arqueólogos quando se propõem a analisar e interpretar vestígios potencialmente importantes para compreensão do passado, quase sempre se deparam com outras práticas de conhecimento. A validade dessas práticas vem sendo bastante debatida teoricamente há mais de 30 anos, com grande influência das reflexões feministas, movimentos indígenas, entre outros, nos quais é central a defesa do fazer científico mais ético e justo, com práticas politicamente engajadas e socialmente conscientes (Atalay, 2006; Haber, 2014).

Em maior ou menor grau, os objetos de análises arqueológicas passam pela chave da alteridade, constituída quer por temporalidades distintas, quer por diferentes grupos de interesses, por vezes distintos culturalmente, e, via de regra, indiferentes ao conhecimento técnico-científico ao qual, nós, como arqueólogos, nos dedicamos a construir. Quando a alteridade está na equação composta pelo arqueólogo e a materialidade, a relação pode aparentemente ser mais simples. O mesmo não ocorre quando, além dos dois primeiros termos, se somam os coletivos locais (comunidades, reivindicantes e stakeholders diversos): arqueólogos se veem diante de alteridades cujas práticas de conhecimento são sensíveis, experimentais e/ou fenomenológicas, que, como pesquisadores, não dominam, embora um dos nossos objetivos seja justamente traduzir tais práticas. Uma questão colocada às práticas arqueológicas em contextos comunitários diversos é: como sincronizar o que sabemos sobre as perspectivas locais com o conhecimento construído pela disciplina?

Obviamente a tarefa não é simples, pois o que está em jogo são temporalidades, tecnologias e ontologias distintas. Se consideramos que ontologias são os acervos de pressupostos sobre tudo aquilo que existe acionados diante de encontros pragmáticos (Almeida, 2013), nos deparamos com uma noção bastante ampliada sobre as formas como os conhecimentos são produzidos. Ontologias são múltiplas, podem convergir, embora na maioria das vezes sejam incompatíveis entre si. No entanto, se até pouco tempo

\footnotetext{
${ }^{2}$ A categoria social arigó é bastante específica no contexto de classificação relacional de pessoas no médio Solimões (Santos, 2012). É reservada aos migrantes que vieram do Nordeste brasileiro, recrutados pelos seringalistas, no auge da economia gomífera; ou na década de 1940, como Soldados da Borracha, e submetidos ao controle de um patrão por um sistema de aviamento. Os arigós podem ser descritos como bravos por diferentes motivos, entre os quais sua insistência em brigar por motivos considerados fúteis, pelo controle rigoroso que exercem sobre as mulheres de seus grupos e pela coragem a eles atribuída (Santos, 2012: 64). Entre os moradores do lago Amanã, lança-se mão do termo nas narrativas sobre situações nas quais as pessoas demonstram falta de conhecimento sobre a floresta ou sobre o modo de vida local (Gomes, 2016:102).
} 
qualquer dimensão ontológica da prática arqueológica não havia sido colocada em cheque na disciplina, felizmente esse quadro vem se reconfigurando (Alberti, 2016; Alberti \& Marshall, 2009; Holbraad, 2012; Reis, 2017; Haber, 2016).

Um conceito central para enfrentar os desafios que decorrem de tentativas de superar desajustes cosmológicos na prática arqueológica é o que poderia ser traduzido como "entrelaçamento de conhecimentos" (braidedknowledge). Nesta ideia, procura-se articular o conhecimento local e "dados" arqueológicos para que ambos confluam para a "criação de novas e texturizadas interpretações do passado" (Atalay, 2012:27). Embora não seja inédita, a ideia é uma alternativa para as abordagens multivocais criticadas na literatura. Há também a metáfora dos sítios arqueológicos como "nós de redes" e "entrecruzamentos de teias" (Ingold, 2011), lançadas para explicar a complexidade de sentidos que podem ser atribuídos aos vestígios materiais do passado e que só podem ser compreendidos a partir de suas relações (Machado, 2017).

Uma posição mais desafiadora é lançada por Bezerra (2017), que oferece reflexões teóricas interessantes a partir de seus trabalhos com comunidades contemporâneas na Amazônia em relação a objetos ditos arqueológicos. Sua proposta mais recente é deslocar a centralidade do conhecimento produzido pela Arqueologia enquanto disciplina para constituir elementos heurísticos. Não se trata exatamente de focar nos emaranhados entre pessoas, lugares e cultura material, mas antes um "desemaranhamento" do conhecimento científico que permita o (re)conhecimento de outras dimensões que prescindam da explicação arqueológica.

Consideremos, por exemplo, as formas pelas quais são identificados sítios arqueológicos. Embora no Brasil não exista um consenso sobre a definição desses lugares, e para além da discussão abrangente sobre os critérios e metodologias de identificação e classificação, basicamente sítios arqueológicos são encontrados devido à procura de marcas antrópicas na paisagem que indiquem ocupações humanas no passado. Essas marcas envolvem desde os vestígios de cultura material às fontes de matéria-prima e recursos variados.

Neste texto quero salientar que buscar por marcas antrópicas é uma questão que reside também em um caráter ontológico, e não exclusivamente metodológico. Como etnografias variadas podem ilustrar, a escolha de um lugar para morar envolve os aspectos de subsistência, mas abrange uma rede complexa de significações, percepções e relações entre agentes humanos e não-humanos, que pouco ou quase nada têm sido exploradas na arqueologia (Para exceções ver Cabral, 2014, 2015, 2017; e Machado, 2012, 2014).

Para argumentar em favor de maior atenção sobre esse aspecto, gostaria de apresentar meu próprio contexto de pesquisa para propor uma inversão na lógica usual que arqueólogos explicam as sucessivas ocupações dos lugares, principalmente entre populações que não possuem continuidade histórica, cultural ou étnica. No lago Amanã a existência de seres não-humanos, os encantados, que habitam a mata e o próprio o lago e agem conscientemente, faz parte do repertório para explicar estratégias de uso de recursos e dinâmicas da ocupação ribeirinha.

\section{PAisAgens Na ARQUeOlogia AmaZÔNICA}

Na Amazônia, um ambiente tropical e úmido, os vestígios materiais sofrem com as péssimas condições de conservação. Os índices mais usuais para a identificação e localização de sítios arqueológicos são os vestígios da tecnologia cerâmica, composição florística e os diferentes graus de transformações paisagísticas, 
como a formação de solos antrópicos (a terra preta de índio), construções com solos e aterros, formação de lago artificiais, entre outras marcas que, em alguns casos, são monumentais, como os geoglifos (ArroyoKalin, 2008; Heckenberger \& Neves, 2009; Schaan, 2004; Schaan et al, 2008).

As pesquisas arqueológicas na região ajudam a desconstruir a noção de um ambiente prístino e intocável, fomentado por diferentes instituições e politicamente orientadas para a conservação da biodiversidade. Na Reserva de Desenvolvimento Sustentável (RDS) Amanã, particularmente, as pesquisas fornecem subsídios para uma nova visão sobre a Amazônia, isto é, um ambiente culturalmente construído e dinâmico.

Amanã é uma Unidade de Conservação localizada na porção central do Estado do Amazonas, ao norte do rio Solimões, no interflúvio do rio Negro e rio Japurá (Figura 1). Possui 2.313.000 hectares e abrange parte dos municípios de Barcelos, Maraã, Coari e Codajás. Dividida entre zonas de proteção integral e de uso sustentável, esta última zona é formada por setores políticos que compõem instâncias de organização comunitária.

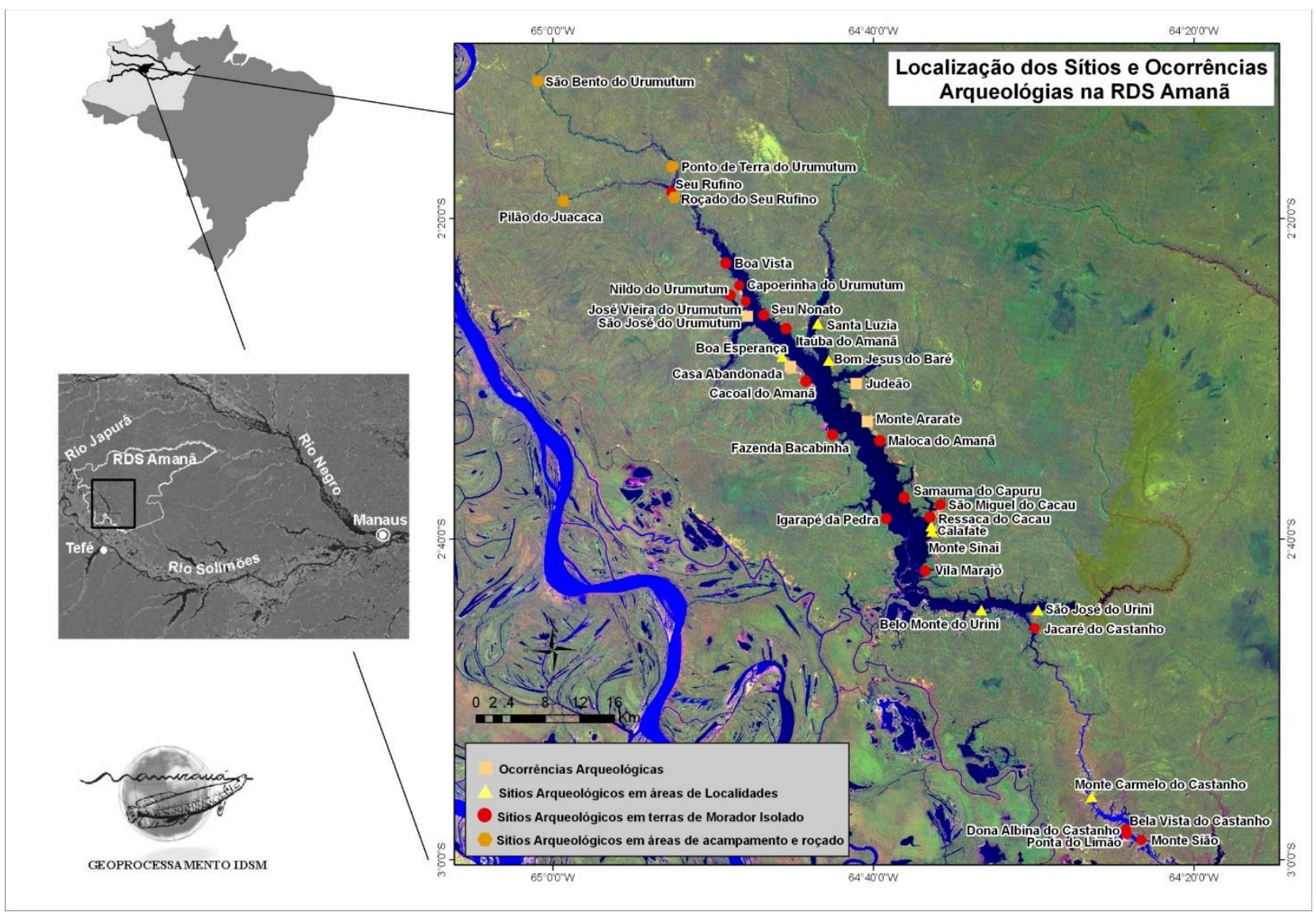

Figura 1: Localização do Lago Amanã e limites da RDS Amanã com indicação dos sítios arqueológicos identificados (Fonte: Geoprocessamento Instituto Mamirauá).

As pesquisas arqueológicas têm como pressuposto que a construção de uma história cultural daquela região deve compreender os vestígios das ocupações pré-coloniais, mas também as dinâmicas de uso do território contemporâneo. Entre os principais motivos dessa orientação está o próprio contexto sociopolítico da pesquisa, já que na legislação brasileira esta categoria de área protegida busca conciliar pesquisa científica e conhecimento tradicional para melhor uso dos recursos naturais, a fim de garantir a qualidade de vida das 
comunidades tradicionais e efetiva proteção de áreas de interesse de conservação da biodiversidade (Queiroz et al, 2006).

O lago Amanã é habitado por uma população de aproximadamente 4 mil pessoas, havendo aqueles que se identificam como ribeirinho, caboclo, arigó, amazonense ou indígena. Essas categorias fazem parte de um sistema relacional de classificação social bastante complexo relacionado a diferentes critérios étnicos, de descendência e compadrio (Lima, D. 1999; Santos, 2012).

$\mathrm{Na}$ Amazônia Central a produção arqueológica dialoga em diferentes graus com o tema da transformação e construção de paisagens (Neves, 2013; Neves \& Petersen, 2005;Moraes, 2013), mas ainda são escassas as análises que lidam com a dinâmica de ocupação territorial, ocupando-se em compreender o estabelecimento de assentamentos, funcionalidade de sítios, áreas de atividades e de exploração de recursos, entre outros aspectos que produziriam marcas materiais e visíveis no registro arqueológico.

Os estudos etnoarqueológicos voltados especificamente para o tema da paisagem estão inseridos em um quadro teórico mais amplo da disciplina, empenhados em compreendê-la como ferramenta para formulação de modelos de adaptação e exploração de recursos. Nessa perspectiva, o foco está na variabilidade espacial dos registros e sítios arqueológicos, resultado de ações diversas que informam sobre dinâmica dos processos de deposição material (Schiffer, 1987; Binford, 1983). Há uma literatura bastante abrangente que pode ser consultada para auxiliar na interpretação e análise das relações entre os registros materiais e disponibilidade e distribuição dos recursos, além dos processos de continuidade e ruptura entre ocupações, em escala local e regional (Binford, 1982, 1983; Heckenberger, 2001, 2005; Politis, 1996; Silva, 2000).

O universo fenomenológico das paisagens e as relações das pessoas com os lugares e seus territórios tornaram-se um tema caro à Etnoarqueologia, cujas análises exploram as múltiplas dimensões das paisagens, recorrendo muitas vezes à ideia de palimpsesto e lançando mão de adjetivos diversos para oferecer argumentos mais próximos da complexidade de relações que envolvem o tema. Destaco a produção arqueológica e etnoarqueológica, que trata as paisagens como significativas e contingentes (Barton et al., 2004; Zedeño \& Browser, 2009), tradicionais, sagradas, culturais e sociais (Whitridge, 2004, Stewart et al., 2004) e dotadas de história e temporalidade (Ferguson et al, 2009; Zedeño, 1997; Ingold, 2000; Para Amazônia brasileira ver Silva, 2015, 2013, 2000; Silva \& Garcia, 2015; Silva \& Stuchi, 2013).

Uma etnoarqueologia das paisagens poderia ser entendida pelo estudo específico dos modos pelos quais os grupos nativos, coletivos, parcelas ou indivíduos compreendem e significam as paisagens, bem como suas ações sobre elas. Os estudos de caso pontuam como esses significados são alocados em virtude não apenas das concepções culturais e sociais, remetendo assim a cosmologias e tradições específicas, mas também das relações de memória, identidade e experiências individuais. A principal contribuição dessas análises é ampliar o background de significados das paisagens, oferecendo uma visão mais integrada entre registros materiais e sentidos (Lane, 2008).

Um eixo fundamental da perspectiva etnoarqueológica é entender como as populações contemporâneas usam o espaço na exploração, manutenção e transformação dos recursos naturais, e como os resultados materiais desses diferentes comportamentos influenciam na formação dos registros arqueológicos e na construção e transformação das paisagens (Silva, 2009). Talvez a principal contribuição de análises do tipo é mostrar as diferentes manifestações da preferência pela ocupação e reocupação de locais previamente antropizados. Mas se há uma extensa produção de dados sobre a dinâmica espacial de diferentes populações 
indígenas (Heckenberger, 2005; Silva, 2000; Silva \& Stuchi, 2010), ainda são pontuais aqueles estudos dedicados às populações ribeirinhas (Machado, 2010, 2012).

Nos contextos que as populações contemporâneas não possuem vínculos históricos ou étnicos com os registros arqueológicos, a explicação pela preferência de uso e assentamento estabelecidos em espaços previamente antropizados recaí na perspectiva economicista. Entretanto, encarar essas escolhas culturais sob uma perspectiva histórica, e de longo prazo, revela questões importantes sobre as relações entre passado e presente, não necessariamente contingenciais.

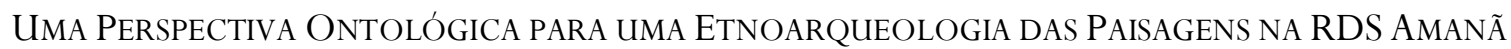

Estudos etnobotânicos e etnográficos acerca das técnicas agrícolas no Lago Amanã destacam que as áreas de terras pretas e a proximidade de "pontas" de terra firme com acesso estratégico às vias de circulação e aos recursos foram os principais critérios na escolha da área de moradia ou de uso: "escolha desses lugares enfatiza a presença de concentrações significativas de plantas úteis, o que reforça a ideia de uma reincidência entre lugares possivelmente manejados no passado e reutilizados hoje" (Furquim \& Rognan, 2014:63).

Há preferência por espaços previamente antropizados, e, ao considerar a sequência dessas escolhas culturais sob uma perspectiva histórica e de longo prazo, as relações entre passado e presente podem ser abordadas através de marcadores ecológicos (Figura 2). Os indicativos para a ocupação podem ser regidos por critérios relacionados às condições ecológicas e semelhantes às observações arqueológicas ${ }^{3}$ : as formações florísticas mais suscetíveis de supressão (capoeira) ou úteis, o regime de enchente e vazante das águas e as distâncias para áreas de captação de recursos, como a caça, coleta e extração. Contudo esses não são critérios exclusivos. Para essas escolhas podem ser ponderados graus de perigos que envolvem dimensões e mundos diversos, visíveis a partir de diferentes estados de consciência ou experimentados nos encontros pragmáticos da vida diária.

O lago Amanã, além de sua importância econômica, é essencial noutros aspectos da dinâmica social. Se configura como local de passagem, trocas e vivências, e também como fonte de um repertório cosmológico que reúne seres não-humanos, conhecidos como encantados. No universo cultural das sociedades ribeirinhas amazônicas, postula-se o reconhecimento da existência de seres com o poder de transformar sua aparência e com os quais se estabelecem relações sociais (Wawzyniak, 2012:18).

Até pouco tempo atrás, as existências de seres como curupira, cobra grande e boto, entre outros, eram consideradas termos do folclore popular e lendas. Na bibliografia antropológica sobre populações ribeirinhas, são recorrentes citações aos seres que se transformam em outros, até mesmo em humanos, capazes de causar distúrbios físicos e psicológicos nas pessoas bem como de regular e afetar o corpo e a vida cotidiana individual e coletiva (Barros, 2017; Carvalho, 1998; Figueiredo \& Barros, 2016; Galvão, 1976; Harris, 2000; Maués, 1997; Nungent, 1993; Lins e Silva, 1980; Smith, 1996; Wagley, 1988; Wawzyniak, 2008; 2012). Análises com diferentes focos que registram ou se debruçam sobre a existência desses seres vêm sendo desenvolvidas

${ }^{3}$ É comum nos contextos de ocupações contemporâneas a reocupação de sítios arqueológicos. Entre os fatores mais usais para a escolha de habitar tais lugares estão marcas de manejo de espécies vegetais. Algumas vezes os vestígios arqueológicos, como cerâmicas fragmentadas e grandes urnas, contribuem para a escolha dos locais de assentamento, pois são considerados como indicadores de antropogênese anterior dos lugares (Machado, 2012). 
também no médio Solimões (Alencar, 2002; Câmpera, 2017; Lima-Ayres, 1992; Lima, 2013; Dutra \& Santos, 2014).

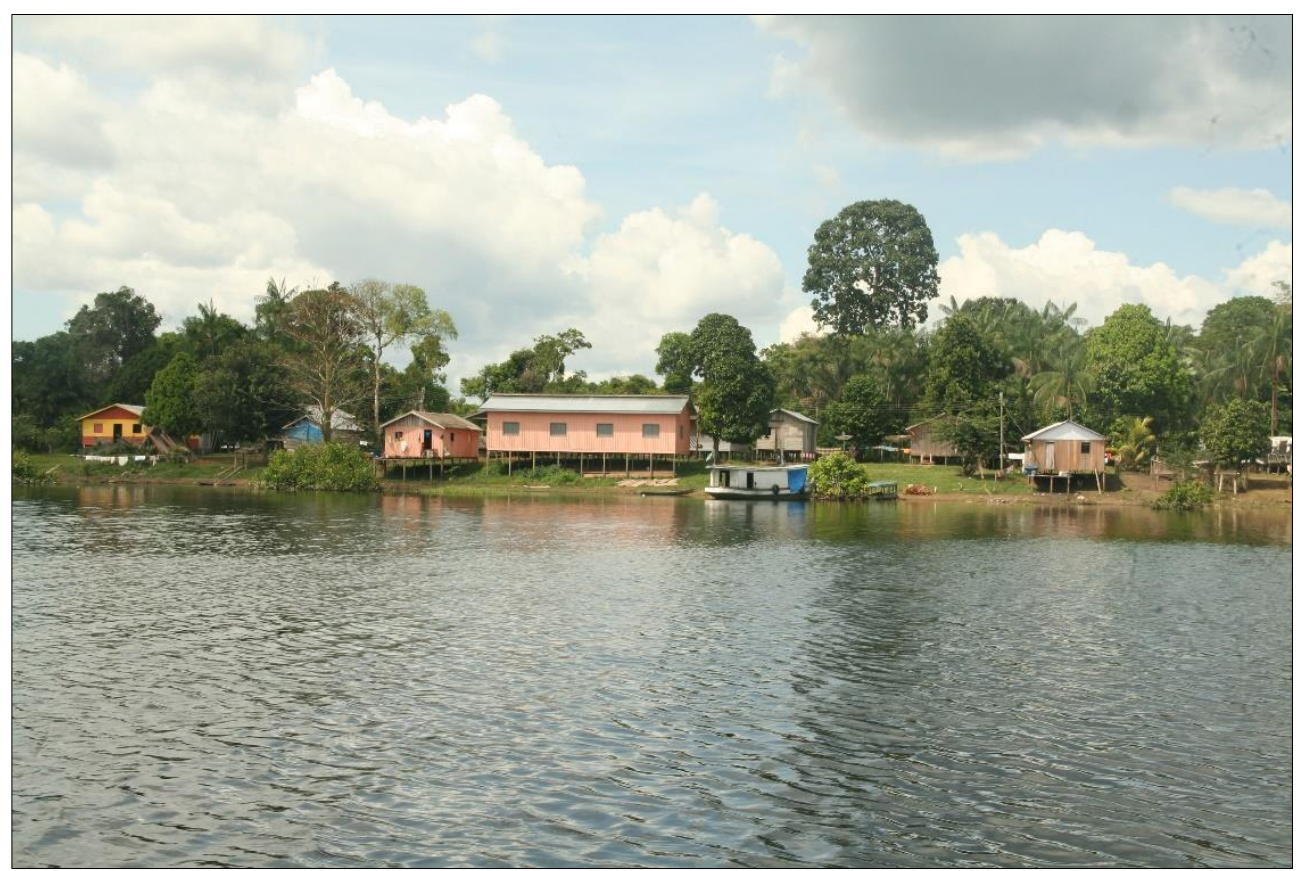

Figura 2: Exemplo de um assentamento típico na RDS Amanã. Casas alinhada às margens do principal curso hídrico, o lago Amanã, com áreas de pomar, denominados localmente de sítios, aos fundos das residências, onde se concentram manchas de solo antrópico fértil (Terra Preta), além de cerâmicas arqueológicas (Fotografia da autora, agosto de 2017).

Entre os moradores do Amanã, esses seres fazem parte das narrativas contadas entre gerações, nas quais figuram histórias de caça, em que o caçador encontra algum desses entes pela mata e se perde, não conseguindo voltar para sua canoa. Há relatos de pescadores que se afogaram depois de ter sua canoa revirada pelo boto ou de famílias que, voltando da roça, escutaram o assovio da Curupira. Como há seres encantados, há também lugares encantados, ilhas e lagos, os quais se constituem como moradas (Câmpera, 2017: 79).

Há aqueles seres do mundo subaquático e aqueles da floresta. Nesta cosmologia ribeirinha, seres com poder de encantamento e agenciamento (animais, humanos, objetos, espíritos), os quais se transformam, circunstancialmente, uns nos outros, são apreendidos como pessoas com quem se pode estabelecer relações sociais, particularmente "acordos" (Wawzyniak, 2012:19).

Em sua tese, Alencar (2002) descreve a noção de encante na cosmologia de comunidades do médio Solimões (RDS Mamirauá, vizinha de Amanã), marcando distinções entre os ambientes de várzea e terra firme:

Na várzea existe a mãe-do-mato, a mãe-d’água; o boto; a cobra-grande. O boto tem a capacidade de assumir forma humana e de levar as pessoas para seu mundo, o encante, que são cidades situadas no fundo dos rios e lagos, $e$ lá encantá-las na forma de boto, de cobra. Na terra firme existem outros seres que não são encontrados na várzea: o Mapinguari, a mãe-da-mata,e a Curupira. Esses seres da terra firme partilham o mesmo plano dos seres humanos, ou seja, moram em cima da terra, ao contrário da maioria dos seres da várzea que habitam num outro plano do cosmo, no fundo dos rios. Isso reforça a importância que o rio possui na vida do morador da várzea, sendo fonte permanente de mudanças, de transformações e continuidade de um modo de vida muito peculiar. (ALENCAR, 2007:200). 
Sobre esses seres, Lima (2013) destaca seu caráter transformacional:

Os encantados são seres dotados do poder de transformação entre um corpo animal e um corpo humano, que é o meio pelo qual se manifestam e estabelecem comunicação com as pessoas. Costumam aparecer em festas e seduzir as moças com quem dançam. Apesar de não serem claramente malignos (mas sim malinos, uma expressão amazônica próxima do sentido de travesso ou traquina), os botos representam perigo porque podem atrair a pessoa para a cidade do encante, onde moram, descrita como muito iluminada e magnificente, localizada no fundo do rio. (...)Outra forma animal, além do boto, é a cobra grande, que pode se apresentar como um navio encantado, muitas vezes carregado de mercadorias - um signo importante nas narrativas de contato de povos ameríndios (Albert e Ramos 2002). A cobra grande, como o boto, é considerada um animal que pode ou não ser um encantado. (LIMA, 2013:177).

A cobra grande, especificamente, é um ser extremamente poderoso e que demanda dos moradores diversos cuidados. Entre meus interlocutores, a existência de lugares específicos que abrigam a casa da cobra grande no mundo subaquático pode ser mencionada com o alerta sobre o perigo desses lugares, embora façam parte do sistema de uso atual. Eles possuem marcas físicas mensuráveis que destacam características das moradias desses seres não-humanos.

A existência desse ente é tão factível e difundida no lago Amanã, que um estudo sobre a ecologia de ilhas de vegetação flutuante, localmente chamadas de matupás (Figura 3), identificou relatos que descrevem o matupá como a casa da cobra-grande e este ente como "mãe dos lagos" ou "mãe d'agua", protetora da vida aquática e da água (Freitas et. al., 2015).

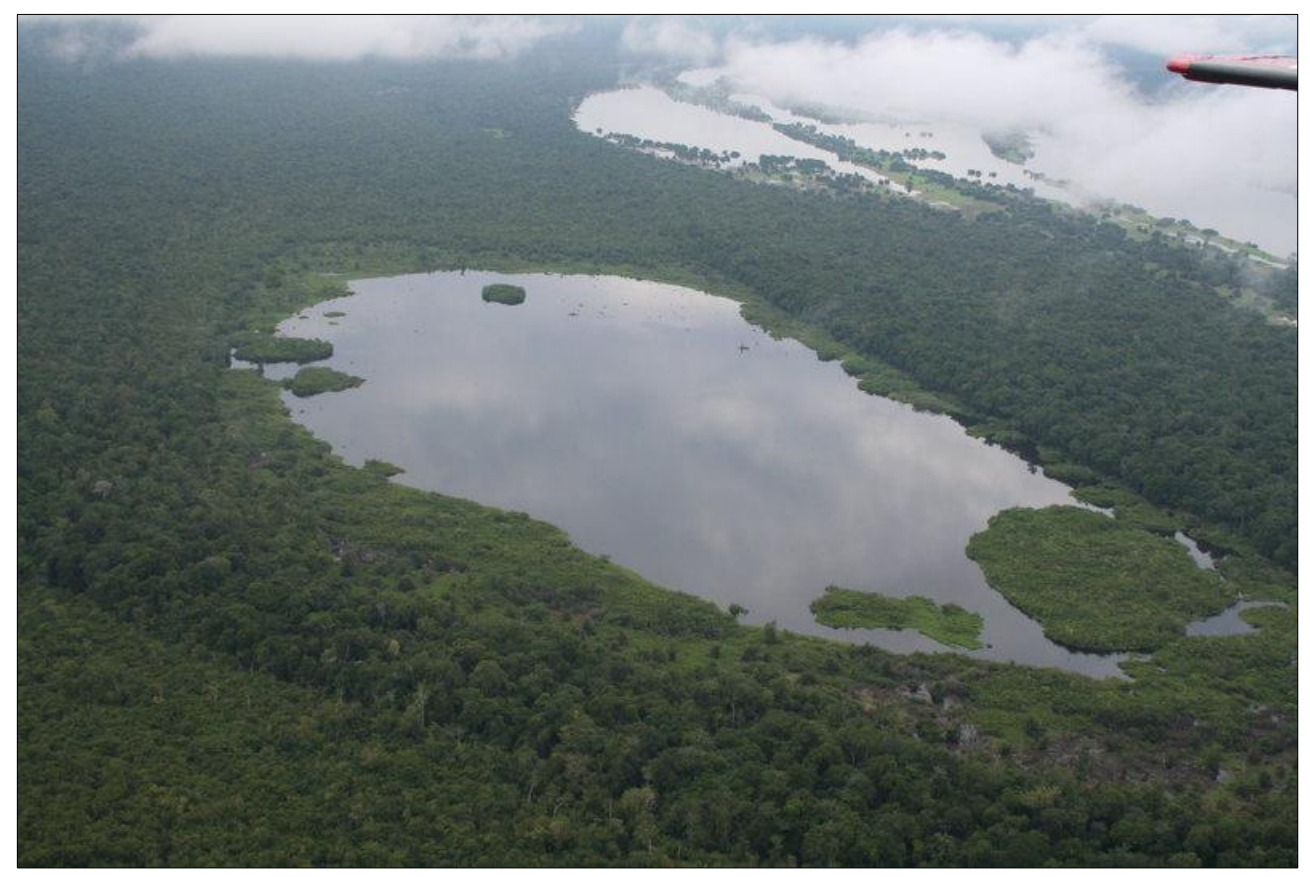

Figura 3: Fotografia aérea de matupás localizados em um lago na RDS Amanã, locais considerados moradas de cobra grande (Fotografia de FlorianWittmann/ Fonte: Freitas, 2013).

No lago Amanã, os seres que dominam a mata/floresta figuram como donos de animais e protetores. São a curupira, o mapinguari e a mãe da mata, os quais andam por toda a floresta e têm como missão cuidar dos animais e punir aqueles que caçam de maneira descontrolada. A onça, que, quando encantada, apresenta-se como homem ou mulher, também faz parte desse repertório cosmológico, podendo ter a capacidade de arremedar (imitar a vocalização) outros animais para atraí-los (Câmpera, 2017: 110; Macedo et al, 2016:105). 
A curupira é o principal ente relacionado à caça, sua característica é a habilidade de fazer pessoas se perderem na floresta ao assumira aparência humana, podendo se transfigurar no corpo de uma pessoa conhecida daquela que está andando pela mata e chamá-la para dentro da floresta.

Tendo em vista esse contexto cosmológico, a lógica inicial com a qual somos levados a determinar marcadores ecológicos e antrópicos que incentivam a ocupação humana pode ser colocada em outros termos. Há determinados elementos como as relações com entes diversos, como os encantados, que se constituem como marcadores ontológicos para a ocupação. No lago Amanã há a certeza nas teorias "empíricas" locais e uma rede de suposições existenciais de relações causais entre os encantados e suas interações com o mundo humano, que contribuem diretamente para a dinâmica de ocupação e exploração de recursos. Sobre esse fato, tomamos como exemplo a experiência da caça entre ribeirinhos.

\section{A CAÇA E AS IMPLICAÇÕES DAS RELAÇÕES ENTRE Humanos E NÃO-Humanos}

Nas etnografias de sociedades amazônicas se destacam as dimensões ontológicas peculiares a partir da noção perspectivista das relações entre humanos e outros entes, nas quais estão contemplados os regimes de uso de recursos variados para a reprodução biológica e social dessas sociedades. A caça especificamente é uma prática que dá sentido a diversas esferas da socialidade e parece figurar como uma fonte imprescindível nessas etnografias (Viveiros de Castro, 1987; 2002; Fausto, 2001; 2008; Aparício, 2014). A principal contribuição dessas análises é complexificar uma atividade fundamental para muitos grupos humanos, propondo um contraponto aos estudos sustentados pela teoria de forrageamento ótimo, que demonstram que caçadores tendem a direcionar seus esforços para abater determinadas espécies cujo benefício energético é maior (Stephens e Krebs 1986; Ghilardi-Jr e Alho, 1990).

Entre as análises etnoarqueológicas para a região, o trabalho de Politis (2007) entre os Nukak, um grupo caçador-coletor localizado na Amazônia colombiana, explora algumas relações entre a caça e cosmologia, com interesse arqueológico. Na cosmologia Nukak, como outros grupos, temos a existência de diferentes mundos bem como animais que habitam aldeias e abrigos. A anta é o espírito animal mais poderoso no nível “subterrâneo", tão poderoso que o jaguar pode ser mantido por ela como um animal de estimação. A conexão entre os diferentes mundos é criada pelas jornadas dos antepassados espirituais, que tomam caminhos que ligam o mundo intermediário ao mundo de cima (Politis, 2007: 89).

Uma característica interessante nessa cosmologia é em relação aos "salados" ou "saltlicks", chamados regionalmente na Amazônia brasileira de barreiros ou chupadores. São áreas de solo encharcado ao menos por parte do ano, onde animais suprem suas necessidades por nutrientes minerais, principalmente o sódio (Emmons \& Stark, 1979). Enquanto que, para muitos grupos amazônicos, esses lugares são preferidos para a caça de grandes mamíferos, entre eles, a anta, os Nukak os consideram como "portais" usados por diferentes animais (como a anta, jaguar, veado e outros) para emergir do submundo à noite. Nesse sentido, são lugares sagrados e raramente visitados. Enquanto os Nukak proscrevem a anta, os Kakwa, Yukuna, Hotï, também caçadores-coletores, e muitos outros grupos amazônicos caçam ativamente e matam esse animal à noite nesses baixios.

Contrariamente às explicações materialistas, baseadas na noção que características ecológicas particulares da presa são determinantes na exploração de recursos faunísticos, etnografias demonstram que a 
escassez ou a abundância de determinada espécie não são vetores fundamentais para estabelecimento de tabus e padrões de consumo. Entre os Achuar, Descola (1994: 338) mostra de forma convincente que a caça de grandes animais e supostamente escassos é intensamente praticada, como também a proibição de caças de animais menores e abundantes. Entre os Siona e Secoya do nordeste do Equador, a anta é caçada e consumida em todas as oportunidades, enquanto o veado, uma espécie mais abundante, é caçado raramente, devido a seus "espíritos malignos” (Vickers, 1989: 302).

De acordo com Aparício (2014:39), entre os Suruwaha, grupo que tradicionalmente ocupa o interflúvio do Purus, os animais eram pessoas, que em certo momento viveram transformações que lhes deram a aparência peculiar de cada espécie. Nos mitos, as antas, queixadas, iraras, sucurijus, são elementos recorrentes que se referem à dinâmica transformacional das pessoas que "viraram animais", tornando-se para os humanos “ex-pessoas”. Para os Suruwaha, há uma condição originária própria de humanos que, alterada pela quebra da socialidade (cujas transformações sempre aparecem como decorrência de conflitos diversos), dá origem a um novo estado de humanos-transformados-em-animais. Essa percepção da passagem de humanos a animais vinculada a conflitos de socialidade está também presente em outros cenários amazônicos, sendo manifesta e atualizada na experiência da caça, na qual ocorre o conflito de socialidade entre os humanos e os animais, que são transformados em presas (Aparício, 2014:47).

Destacar os elementos socioculturais da caça tem o sentido de mobilizar a riqueza de saberes, práticas, lógicas e sociabilidades que a norteiam. Os exemplos acima mencionados referem-se a populações indígenas. Entre populações ribeirinhas também são registrados complexos sistemas locais normativos que envolvem multiplicidade de fatores: 1) animais considerados “reimosos" restringem o consumo de determinadas espécies classificadas como tabus (Murrieta, 2001; Pezzuti, 2004; Silva, 2003); 2) visagens inibem os caçadores de frequentar determinados lugares, e o medo da panema os leva a tomarem certos cuidados em suas atividades e a repensarem suas práticas (Almeida, 2013; Da Matta, 1973; Galvão, 1976); 3) a existência de entes que fazem parte da cosmologia e dos sistemas tradicionais que em muitos casos reconhecem áreas sagradas ou protegidas por tabus onde reside um "Mestre de Animais," "Dono da Caça," ou "Caipora/Curupira", que protege os animais de caça, além de punir os seres humanos por transgressões (Almeida, 2013; Carneiro da Cunha \& Almeida, 2002; Reichel-Dolmatoff, 1976; Shepard Jr., 1999).

A caça de subsistência na RDS Amanã trata-se de uma atividade preferencialmente diurna, seletiva, predominantemente masculina, com uma gama de estratégias, instrumentos e técnicas, que contemplam grandes mamíferos, juntamente com cracídeos e quelônios de importância especial em ambientes alagáveis (Valsecch, 2012).

Pesquisas e monitoramentos, com fins de caracterização do padrão de abate e consumo de caça, informam que a preferência alimentar é o principal mecanismo de seleção das espécies, podendo aumentar a pressão de abate sobre alguns animais (Valsecchi \& Amaral, 2009; Prado et al., 2012). Os animais mais caçados são a cutia (Dasyprocta fuliginosa), queixada (Tayassu pecari), paca (Cuniculus paca) e jabuti (Chelonoidisdenticulata) (Vasconcelos Neto, 2016:38). Outro fator importante que influencia as atividades de caça é a variação do nível dos rios. O aumento no nível das águas facilita a caçada devido à formação de ilhas nas quais os animais procuram refúgio e alimentação (Morcatty \& Valsecchi, 2015). Além desses fatores mensuráveis numa perspectiva naturalista, outros se somam, podendo ser considerados também fundamentais, como os conceitos a seguir. 
A reima é um sistema classificatório de restrições e proibições alimentares, geralmente aplicados a pessoas em estados físicos e sociais de maior susceptibilidade, como enfermidades e gravidez (Maués e MottaMaués, 1978). No lago Amanã, faz parte do repertório das noções de corpo e doença e processos de cura (Câmpera, 2017: 69). Entre ribeirinhos da RDS Peagaçu-Purus, Vieira (2013) registrou que além do efeito físico em doentes, há aqueles que temem em perder a própria vida pelo consumo de carnes reimosas. Naquele contexto é conferido um elevado grau de perigo, sendo a anta um animal com alto índice de rejeição devido a sua reima.

Já panema é um conceito de ampla circulação na Amazônia que designa uma relação entre entes, tão generalizante que Almeida (2013) o compara ao conceito de gravidade. Trata-se de um estado de infortúnio que acomete algumas pessoas, trazendo má sorte às suas atividades, principalmente a caça. Pode ser descrito como um estado do corpo do caçador (algumas vezes apresentando sintomas clínicos, conferir Wawzyniak, 2008:133), transmitido pelo contato inadequado do caçador ou de pessoas na cadeia predatória com partes da presa, como ossos, sangue, cabelos, gordura e carne, com caminhos trilhados ou ainda com cães e instrumentos de predação como espingardas e terçados.

Entre as práticas locais figuram entre os caçadores portar objetos de sorte, como a maçã de boi, ou ser reconhecido como um bom especialista quando captura um quelônio de 13 malhas (Figura 4).
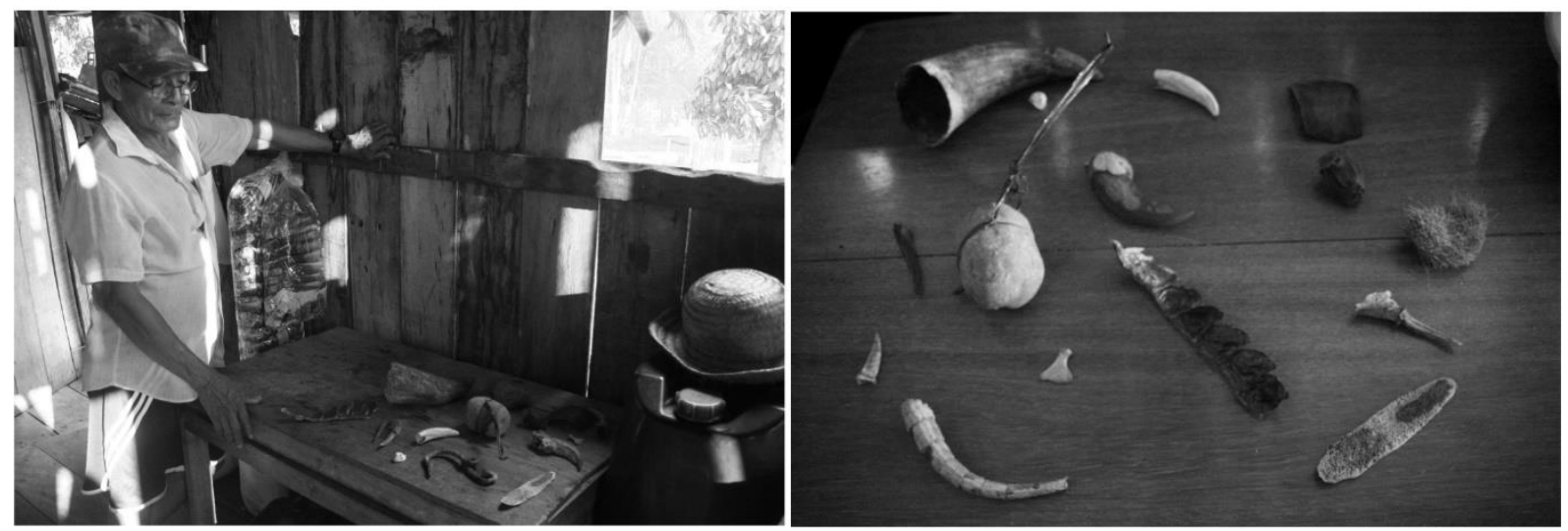

Figura 4: Seu "Jota", caçador experiente, apresentando objetos que mantêm em sua coleção particular, nela estão a maçã de boi, breu branco e malha de jabuti, amuletos e instrumentos de sorte que podem ser levados nas expedições de caça (Fotografia da autora, julho de 2011).

Entre os seringueiros do Acre (Almeida, 2013), ribeirinhos do baixo Tapajós (Wawzyniak, 2008), do Peagaçu-Purus (Vieira, 2013) e do Amanã (Câmpera, 2017), panema está conectado ao tema moral do insulto. $\mathrm{O}$ insulto refere-se à quebra de etiqueta no trato com o corpo do animal. Há insulto se o caçador urinar sobre o corpo do animal abatido, passar a perna sobre ele ou se o amarrar de modo incorreto antes de transportálo. Também existem diversas formas de insultar o animal depois que sua carcaça é trazida para a cozinha da casa, onde suas cinzas e ossos estão perigosamente ao alcance de cães, e também quando a circulação obrigatória da carne entre vizinhos cria risco do contato no consumo por parte de mulheres grávidas ou menstruadas.

Nas comunidades de Amanã, panema é um conceito fortemente difundido e pode ter causas diversas, geralmente relacionadas à prática da caça. O infortúnio da panema pode envolver o compartilhamento da carne caçada (embiara), a frequência de investidas do caçador, se ele passa muitos dias atrás de um animal, se 
uma mulher grávida ou um vizinho invejoso comer da embiara, se uma mulher menstruada passar por cima dos instrumentos usados nas atividade de caça ou pesca, se os restos de um animal caçado forem jogados onde outras pessoas passam ou fazem suas necessidades, se o caçador "bagunçar" o barreiro ou outro local propício para a atividade. Pode ainda estar relacionada ao fato do caçador sair para uma expedição aos domingos ou dias santos, se for abatida uma fêmea grávida ou com filhote. Todas são situações em que o caçador pode ficar panema.

Quando abatida uma fêmea prenhe ou com filhote, de modo a minimizar problemas com a panema, o caçador leva o animal para sua casa para criá-lo. A acolhida, por vezes, permite a nomeação do animal, cujos cuidados são de responsabilidade das mulheres e crianças (Figura 5).

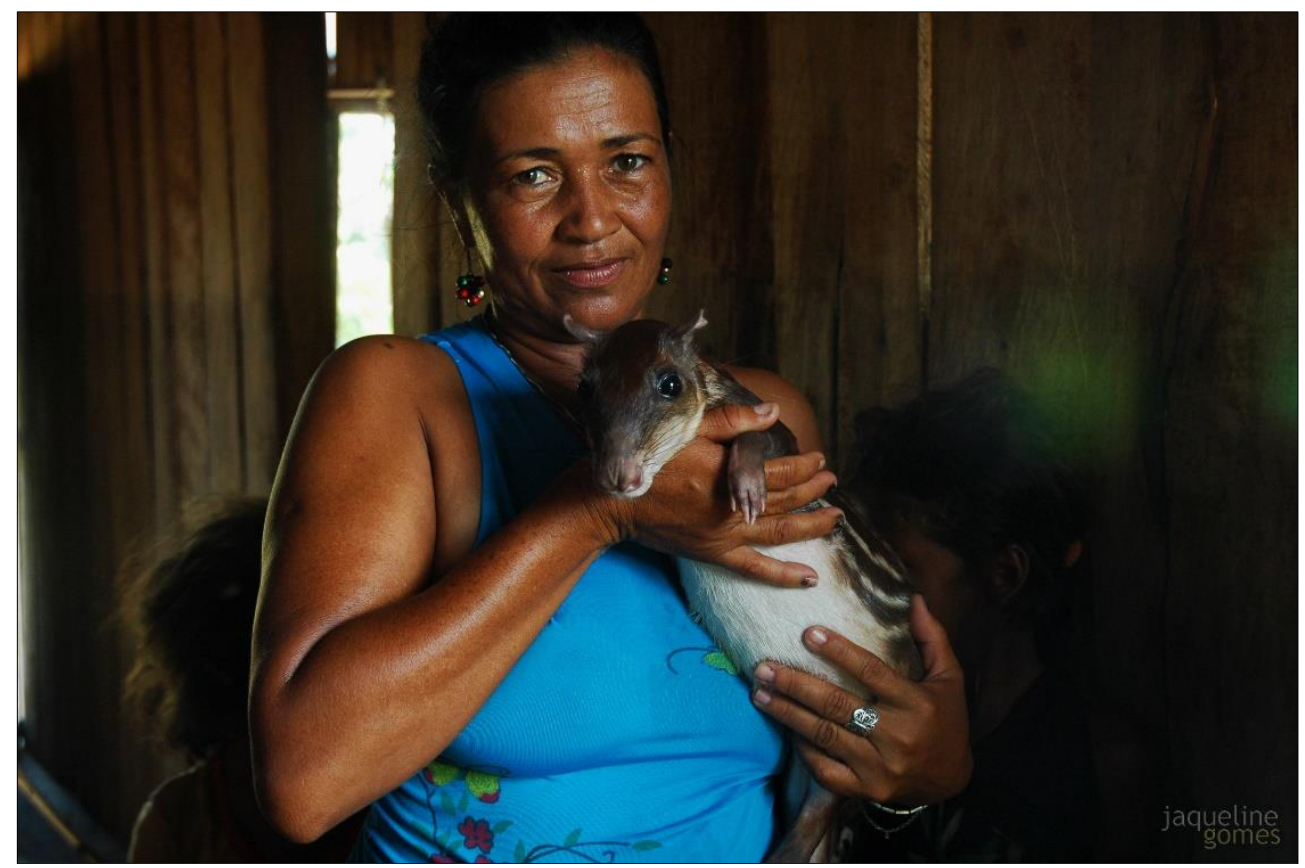

Figura 5: A: Dona Maria, moradora da comunidade Bom Jesus do Baré mostra o filhote de paca que manteve em sua casa decorrente de uma caçada de seu filho (Fotografia da autora, outubro de 2010).

Finalmente, panema não trata da relação de causa e efeito que conecta presa e predador (caça e caçador / animal e homem), mas envolve uma rede recíproca de consumo de caça, além do próprio caçador, cães de caça, espingardas e seres não-humanos que vivem na mata como a Curupira. Exatamente porque é tão generalizado e tão difuso, é algo que se confirma a todo momento pela experiência (Almeida, 2013).

Já a visagem é outro conceito bastante difundido no meio rural, pode ser sinônimo de mizura como entre os moradores de Amanã. Também pode ser entendido como uma aparição, sons de outros seres não identificáveis, mas basicamente, pode ter várias formas, nomes e intenções. Relatos descrevem como um menino que pode fazer o caçador sentir-se mal, caso desrespeite alguma norma de uso da mata. Pode ser relacionado aos sons da Curupira, que ajuda a encontrar animais e a sorva, ou faz a pessoa perder-se no mato; pode ser definida como "a mãe da mata". Na região do Peagaçu-Puru, os mais velhos a associam a um ente, não muito bem caracterizado até então, mas chamado de “dono do barreiro”, invisível, mas perceptível pela audição (Vieira, 2013). 
Na mata, é difícil o caçador que não tenha ouvido mizura ao menos uma vez, não sendo necessário uma situação específica, pois muitos consideram ser inerente àquele ambiente. No entanto, quando o morador duvida de sua existência ou quebra alguma norma cultural, a visagem pode assombrá-lo. Por exemplo, já registrei relatos de visagens quando urnas cerâmicas arqueológicas começaram a ser escavadas pelos moradores quando descobertas.

Há lugares onde sua aparição é frequente, considerados "lugares visagentos", onde o caçador toma maiores precauções ou evita frequentá-los. São comuns os relatos de que depois da pessoa ter sido “assombrada” em determinado local, nunca mais retorna ali. A presença da visagem pode ser associada aos barreiros, lugares usados dentro de uma técnica bastante especializada que a espera de anta. Vieira (2013:53), em uma de suas entrevistas com caçadores, registrou:

Barreiro que chamo é aqueles grandes mesmo, aquelas comedias grande. Aí lá que aparece toda qualidade de mizura. Sabe lá quantos 'insetos' não andam por lá (...). A gente pensa que é gente, pensa que é bicho, quando pensa que não, é a visagem da anta. Só pode ser a mãe do barreiro.

No lago Amanã as nomenclaturas barreiro, chupador e canamã às vezes podem ser usadas como sinônimos, mas fazem parte de um sistema de classificação dessas áreas que ocorrem nas proximidades dos cursos d'água, com inundação periódica ou parcial, e na terra firme em menor número (Ayres, 1979). O tempo que estas áreas duram é variável e, por isso, alguns caçadores zelam os barreiros onde encontram bastante rastro de animais. O zelo implica cultivar a área, fazendo com que aqueles animais focais preferenciais não a abandonem. O zelo também envolve cuidados para não "bagunçar” a área, como lavar o sangue despejado no solo, não tratar a embiara (carne da caça) no local, não urinar, não cuspir.

As narrativas de encontros inesperados com a caça quando no retorno de alguma atividade na mata confere ao caçador status e reconhecimento por parte da comunidade. Os abates oportunísticos são os eventos que corroboram para este reconhecimento do especialista devido sua agilidade, técnica e perspicácia para abater o maior número de animais possíveis (Figura 6).

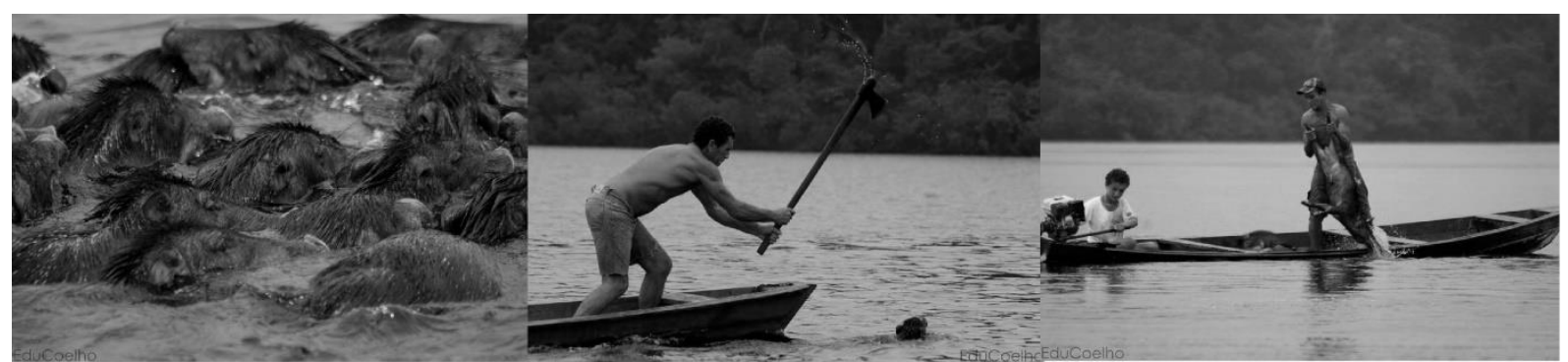

Figura 6: Abate oportunístico de queixada por moradores da Comunidade B. J. do Baré enquanto bando fazia atravessia do lago Amanã. Registros em outubro de 2010 (Fotografias de Edu Coelho).

Entre as estratégias de caça, três se destacam: as expedições de caça, a focagem noturna e a caça de espera, esta última bastante especializada, apesar da primeira estratégia ser mais usada. O percurso pode ser feito a pé ou de canoa. Quando a caçada vai ser realizada nas matas de terra firme, o caçador percorre normalmente uma trilha pré-existente. No lago Amanã, especificamente nas comunidades foco da análise arqueológica, são três as principais trilhas, que foram abertas durante o período de exploração da sorva e 
outros recursos, ainda na primeira metade do século XX. Posteriormente, tornaram-se também fundamentais para as pesquisas biológicas no contexto da criação da unidade de conservação (Figura 8).
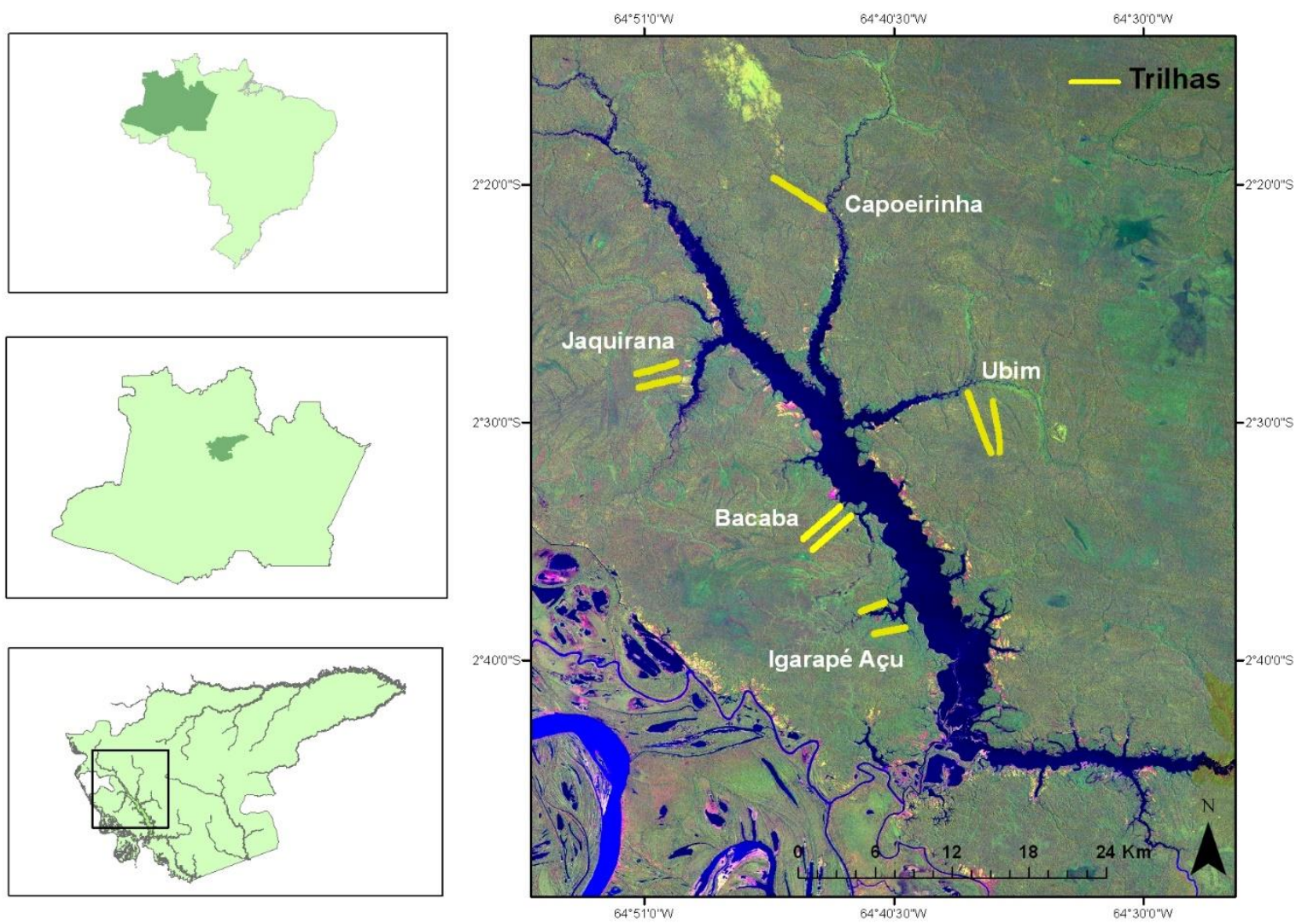

Figura 7: Trilhas para acessos das áreas de caça, usadas também nas pesquisas de monitoramento de fauna.

(Fonte: Geoprocessamento Instituto Mamirauá)

Os caçadores que afirmam gostar da caça de espera em barreiros têm preocupação com quem levar ou informar sobre a existência de um barreiro. A importância do zelo e os demais cuidados relativos a esses lugares demonstram um sistema normativo, com prescrições específicas, sendo o mais enfático a caça da anta. O animal é considerado por muitos caçadores o mais difícil de ser caçado, pois ele pressente antecipadamente o caçador, sente o cheiro de pólvora, caso outro animal tenha sido atirado, o cheiro da fumaça do tabaco a espanta, pode pressentir se a esposa do caçador estiver grávida e, neste caso, nem aparece no barreiro. A este animal pode ser conferida "ciência". Atributos diversos como cabreiro, sistemático, escabreado e sagaz são acionados para esses animais na medida em que parecem formular estratégias para fugirem das emboscadas montadas pelos seus predadores humanos. É comum que a anta avise quando vai morrer através de sonhos.

\section{CONSIDERAÇÕES}

Na RDS Amanã são conhecidos mais de 40 sítios arqueológicos que variam muito no que diz respeito aos seus componentes materiais, espacialidade e dimensões. Essa variabilidade inicialmente foi classificada em quatro fases arqueológicas, a mais antiga delas, um complexo cerâmico local, cuja profundidade cronológica é 
de 3.200 anos (Costa, 2012; Furquim, 2014; Gomes, 2015). Considerando o espectro dos estudos arqueológicos, seria possível formular um modelo que explique o sistema de relações entre os sítios arqueológicos às margens do lago Amanã? Inicialmente estive interessada nesta questão e em compreender em que medida as práticas das populações que ocuparam aquela região no passado pré-colonial deixaram marcas na paisagem, que poderiam ou não influenciar na dinâmica contemporânea de ocupação.

Quando fui levada à casa da cobra grande, especificamente aquela morada me chamou atenção, tratavase de um lugar de fácil acesso, às margens de terreno não alagável, situado na bifurcação entre os igarapés formadores do lago, próximo às entradas para áreas de caça e florestas de castanhas e seringa. Portanto, estratégico se consideramos as fontes de recursos. Posteriormente, através de uma análise cartográfica de mapas disponíveis, percebi que a localização das comunidades contemporâneas e suas respectivas áreas de uso bem como a localização dos antigos assentamentos do processo recente de ocupação, e surpreendentemente, dos sítios arqueológicos já identificados, configuram aquela casa da cobra grande como um vazio de vestígios das ocupações pré-coloniais e contemporâneas. Para minha surpresa, o lugar mencionado no início desde texto, parecia ser evitado.

Considerar a existência de um lugar específico que abriga a casa da cobra grande no mundo subaquático, contribui para compreender a constituição de paisagens? Talvez, principalmente porque não desconsideramos as implicações dessa informação.

As paisagens do lago Amanã estão repletas de marcas físicas mensuráveis que destacam características de moradias de seres não-humanos, que trazem consigo uma noção de perigo, relacionado à própria existência física das pessoas, assim como, ao bem estar das relações sociais.

Este é o caso das relações estabelecidas entre os caçadores/animais/seres não-humanos, que implicam desde os diferentes estados e condições físicas e de saúde explicados pela panema, mas também na existência de lugares específicos, visagentos ou perigosos, e que podem se configurar como lugares que devem ser evitados na territorialidade ribeirinha.

Sobre as informações da prática da caça, ainda que incipientes, vejo que nelas são ativadas noções que fazem parte de uma ontologia ainda um tanto obscura, porque é mais implícita e pressuposta do que explicitada (Almeida, 2013:15), mas que, aliadas à existência de lugares específicos reconhecidos como moradas de seres não-humanos, podem oferecer novas perspectivas para compreender algumas faces das dinâmicas de ocupação contemporânea no lago Amanã.

Determinadas questões me motivam a entender como esses conceitos podem ser operados dentro de uma análise arqueológica. A primeira delas é trazer para discussão a cosmologia ribeirinha, que vem se formando como um corpo específico, alinhada em linhas gerais ao pensamento ameríndio, em contraponto à ontologia naturalista. Talvez mais que uma proposta de análise alternativa da paisagem, neste momento meu exercício reside na negação de um caminho viável, e provavelmente confortável, que seria interpretar estratégias de ocupação contemporâneas através de uma "lógica da semelhança", na qual a dinâmica atual de relação com o território estaria centrada nos critérios locais de indicativos suscetíveis às condições ecológicas, e, portanto, semelhantes as observações arqueológicas.

Contudo, entre os critérios elencados para dar sentido às escolhas para moradia e áreas de uso e de exploração de recursos, as pessoas acionam uma série de relações com seres não-humanos, como procurei demonstrar, por exemplo, através da prática da caça. Por que deveríamos ignorar estes critérios? 
O fato é que de determinadas feições presentes na paisagem, e, portanto, que tangem a materialidade, podem ser consideradas marcadores ontológicos para ocupação humana e nos leva, entre outros desdobramentos, a uma arqueologia das marcas de entes não-humanos. Outro fato é que uma relação de aspectos da caça com esses seres cosmológicos influencia na percepção sobre os lugares bem como nas técnicas e formas de exploração de recursos.

Considerar outra ontologia como ponto de partida ajuda a compreender formas alternativas de engajamento com as paisagens (contemporânea e arqueológica) e pode ao menos, desestabilizar as tradicionais maneiras pelas quais a arqueologia compreende as relações entre sítios arqueológicos e lugares significativos no lago Amanã contemporâneo, oferecendo outra perspectiva sobre os lugares "off site", que parecem ser fundamentais na territorialidade ribeirinha. 
UMA PERSPECTIVA ONTOLÓGICA PARA UMA ANÁLISE ETNOARQUEOLÓGICA DAS PAISAGENS DO LAGO AMANÃ, BAIXO JAPURÁ, AMAZONAS

\section{REFERÊNCIAS BIBLIOGRÁFICAS}

ALENCAR, Edna. 2002. Terra caída: encante, lugares e identidades. 2002. Tese (Doutorado em Antropologia). Universidade de Brasília, Brasília.

ALBERTI, Benjamin. 2016.Archaeologies of Ontology. Annu. Rev. Anthropol. Vol. 45:163-79.

ALBERTI, Benjamin. \& MARSHALL, Yvonne. 2009. Animating archaeology: Local theories and conceptually open -ended methodologies. Cambridge ArchaeologicalJournal, vol. 19(3) : 344-56.

ALMEIDA, Mauro. 2013. "Caipora e outros conflitos ontológicos". R@u-Revista de Antropologia da UFSCar, vol. 5(1): 7-28. São Carlos.

APARICIO, Miguel. 2014. Relações Alteradas - Ideias Suruwaha sobre Animais e Caça. Ilha - Revista de Antropologia , vol. 16: 037-068.

ARROYO-KALIN, Manuel. 2008. Steps towards an ecology of landscape: a geoarchaeological approach to the study of anthropogenic dark earths in the Central Amazon region, Brazil. 232 p .Tese (DoutoradoArqueologia), Cambridge University.

ATALAY, Sonia. 2012. Community-Based Archaeology: Research with, by, and for Indigenous and Local Communities. University of California Press, Berkeley.

ATALAY, Sonia. 2006. Indigenous Archaeology as Decolonizing Practice. American Indian Quartely vol. 30 $(3 / 4): 280-310$

AYRES, J. M. 1979. Aspectos da caça no alto rio Aripuanã. Acta Amazónica, 9 (2): 287-298.

BALEE, Willian. 2006. The research program of historical ecology. Annu. Rev. Anthropol. Vol. 35:75-98,.

BARROS, Flávio Bezerra. 2017. Os caçadores do Riozinho do Anfrísio: Saberes e práticas culturais entre narrativas e imagens. Muiraquitã, UFAC, v. 5, n. 1.

BEZERRA, Marcia. 2017. Teto e Afeto: Sobre as Pessoas, as Coisas e a Arqueologia na Amazônia. GK Noronha, Belém.

BINFORD, Lewis. 1983. Organization and formation processes: looking at curated technologies. in L.R. Binford (Ed.) Working at Archaeology. Academic Press, New York. Pp. 269-286.

BINFORD, Lewis. 1982. The archaeology of place. Journal of Anthropological Archaeology 1(1):5-31.

CABRAL, Mariana. 2017. El ronquido del hacha e otras cosas extrañas. In: PELLINI, J.R., ZARANIN, A; SALERNO, M. (Eds.) Sentidos indisciplinados Arqueología, sensorialidad y Narrativas alternativas. JAS Arqueología S.L.U.

CABRAL, Mariana. 2015. Traces of past subjects: experiencing indigenous thought as an archaeological mode of knowledge. J. Contemp. Archaeol. Vol 2(2):S1-30

CABRAL, Mariana. 2014. E se todos fossem arqueólogos? Experiências na Terra Indígena Wajãpi. Anuário Antropológico, vol. 39: 115-132.

CÂMPERA, Luisa. 2017. O lago encantado e o caminho da chuva: noções de corpo, cura e cosmologia no Médio Solimões. 126 f. Dissertação (Mestrado em Antropologia). Universidade Federal do Amazonas, Manaus.

CARNEIRO DA CUNHA, Manuela \& ALMEIDA, Mauro Barbosa de (orgs.). 2002. Enciclopédia da Floresta: o Alto Juruá: práticas e conhecimentos das populações. Cia. das Letras, São Paulo.

CARVALHO, M. 1998. "De doente a "encantado": o conceito de mecanismo de defesa constituído culturalmente e a experiência de uma vítima de "espírito mau" em uma comunidade rural na Amazônia". In ALVES, P. C. \& RABELO, M. C (Org.) Antropologia da saúde: traçando identidade e explorando fronteiras. RelumeDumará, Rio de Janeiro. 
COSTA, Bernardo L. S. da. 2012. Levantamento Arqueológico na RDS Amanã - Estado do Amazonas. Dissertação de mestrado. Museu de Arqueologia e Etnologia da Universidade de São Paulo, São Paulo, 160 p.

DA MATTA, Roberto. 1973"Panema". In: Ensaios de Antropologia Estrutural. Vozes, Petrópolis. Pp. 63-92.

DESCOLA, P. 1994. In the society of nature: A native ecology of Amazonia. Cambridge University Press, Cambridge.

DUTRA, Juliana \& SANTOS, Rafael. 2014. Experiências de encantamento e a relação dos miranha do cuiú-cuiú com os botos vermelhos (iniageoffrensis). UAKARI.

EMMONS, L.H. \& STARK, N.M. 1979. Elemental composition of a natural mineral lick in Amazonia. Biotropica, 11(4): 311-313.

FAUSTO, Carlos. 2008. Donos demais: maestria e domínio na Amazônia. Mana, 14(2): 329-366

FAUSTO, Carlos. 2001. Inimigos fiéis: história, guerra e xamanismo na Amazônia. EDUSP, São Paulo.

FREITAS, Carolina, SHEPARD, Glenn H., PIEDADE. Maria T. F. 2015.The Floating Forest: Traditional Knowledgeand Use of Matupá Vegetation Islands by Riverine Peoples of the Central Amazon. PLoS ONE 10(4): e0122542. https://doi.org/10.1371/journal.pone.0122542

FERGUSON, T.J.; BERLIN, G.L. E KUWANWISIWMA, L.J. KUKHEPYA. 2009. Searching For Hopi Trails. In: Landscapes of movement. Trails, paths and roads in anthropological perspectives. University of Pensylvania Museum of Archaeology and Anthropology, Philadelphia. pp. 20-41.

FIGUEIREDO, Rodrigo Augusto Alves de; BARROS, Flávio Bezerra. Sabedorias, cosmologias e estratégias de caçadores numa unidade de conservação da Amazônia. Desenvolvimento e Meio Ambiente, Curitiba, v. 36, p. 223 237, 2016

FREITAS, Carolina, 2013. Ecologia, etnoecologia e uso local de matupás na Reserva de Desenvolvimento Sustentável Amanã, Amazônia Central. Dissertação de mestrado. Programa de Pós-Graduação em Ecologia, Instituto Nacional de Pesquisas da Amazônia, 124 p.

FURQUIM, Laura \& ROGNANT, Camille. 2014. Construção e Reapropriação das Paisagens: um palimpsesto de pessoas, histórias e plantas no Lago Amanã - RDSA - AM. In: SOUSA, Marília; CORRÊA, Dávila (Org.). Livro de Resumos. Simpósio sobre Conservação da Amazônia. AM: IDSM; CNPq, Tefé. Pp. 62-63.

FURQUIM, Laura. 2014. Análise Laboratorial do Material Cerâmico do Sítio São Miguel do Cacau e Monitoramento dos Sítios em Área de Comunidade no Lago Amanã - RDSA - AM. Relatório Final apresentado ao CNPq. Tefé, 164 p.

GALVÃO, Eduardo. 1976. Santos e Visagens: um estudo da vida religiosa de Itá; Amazonas. Segunda ed. Companhia Editora Nacional, São Paulo, 202p

GHILARDI-JR, R. \& ALHO, C.J.R. (1990). Produtividade Sazonal da Floresta e Atividade de Forrageamento Animal em Habitat de Terra Firma da Amazônia. Acta Amazonica, 20: 61-76.

GOMES, Jaqueline. 2016. Alteridades e Paisagens na Comunidade Boa Esperança, RDS AMANÃ (AM). Teoria \& Sociedade (UFMG). v.24, p.92 - 114.

GOMES, Jaqueline. 2015. Cronologia e mudança cultural na RDS Amanã (Amazonas): um estudo sobre a fase Caiambé da tradição Borda Incisa. Dissertação de mestrado. Museu de Arqueologia e Etnologia da Universidade de São Paulo, São Paulo, 196p.

HABER, Alejandro. 2016. Al otro lado del vestigio: Políticas del conocimiento y arqueologia indisciplinada. Universidad del Cauca, Sello Editorial, Popayán.

HABER, Alejandro. 2014Interculturalidad epistémica y acción política en la arqueología poscolonial. In RIVOLTA, María Clara (Ed). Multivocalidad y activaciones patrimoniales en arqueología: perspectivas desde Sudamérica. Fundación de Historia Natural Félix de Azara, Buenos Aires. Pp. 47-65.

HARRIS, M. 2000. Life on the Amazon: the anthropology of a brazilian peasant village. Oxford: Oxford University Press, 2000. 
UMA PERSPECTIVA ONTOLÓGICA PARA UMA ANÁLISE ETNOARQUEOLÓGICA DAS PAISAGENS DO LAGO AMANÃ, BAIXO JAPURÁ, AMAZONAS

HECKENBERGER, Michael \& NEVES, Eduardo. 2009. Amazonian archaeology. Annual Review of Anthropolology38: 251-266, 2009.

HECKENBERGER, Michael. 2001. Estrutura, história e transformação: a cultura xinguana da longdurée, 1000 2000d.C. In: M. Heckengerber\& B. Francheto(Orgs.). Os povos do alto Xingu. Rio de Janeiro: UFRJ, 2001, p. 21-62.

HECKENBERGER, Michael, 2005. The Ecology of Power: Culture, Place and Personhood in the Southern Amazon, AD 1000-2000. Routledge, New York

HOlBRAAD, M. 2012. Truth in Motion: The Recursive Anthropology of Cuban Divination. University Chicago Press, Chicago.

INGOLD, Tim. 2011.Being Alive. Essays on movement, knowledge and description. Routledge, Londres.

INGOLD, Tim. 2000. The temporality of the landscape. In: INGOLD, Tim. Perception of the enviroment. Essays on livelihood, dwelling and skill. London/New York: Routledge: 189-208.

LANE, Paul. 2008. The Use Of Ethnography In Landscape Archaeology. In: DAVID, Bruno e THOMAS, Julian (Orgs.). Handbook of Landscape Archaeology. Walnut Creek: Left Coast Press: 237-244.

LIMA, Deborah. 2013.0 Homem Branco e o Boto: o encontro colonial em narrativas de encantamento e transformação (Médio Rio Solimões, Amazonas). Teoria \& Sociedade. Número Especial: Antropologias e Arqueologias hoje.

LIMA, Deborah. 1999. A construção histórica do termo caboclo: sobre estruturas e representações sociais no meio rural amazônico. Novos Cadernos NAEA, v. 2, n. 2:5-32.

LIMA-AYRES, Déborah. 1992. The social category caboclo: History, social organization, identity and outsider's social classification of the rural population of an Amazonian region (the middle Solimões). Tese de doutorado, Universidade de Cambridge, Inglaterra.

LINS E SILVA, T. 1980. Os Curupira foram embora: economia, política e ideologia numa comunidade amazônica. Dissertação (Mestrado em Antropologia) Museu Nacional da Universidade Federal do Rio de Janeiro, Rio de Janeiro.

MACEDO, J. ; SANTOS, R.B.; BRANQUINHO, F. ; BERGALlO H.G . Controvérsias entre a Amazônia rural e a conservação: um estudo sobre a Rede Sociotécnica de ribeirinhos e onças nas Reservas de Desenvolvimento Sustentável Mamirauá e Amanã no Amazonas. Anuário Antropológico , v. 41, p. 99-121, 2016.

MACHADO, Juliana. 2017. Arqueologias Indígenas, os LaklãnõXokleng e os objetos do pensar. Revista de Arqueologia, v. 30, n. 1, p. 89-119.

MACHADO, Juliana. 2012. Lugares de Gente: mulheres, plantas e redes de troca no delta amazônico. 350 p. Tese (Doutorado em Antropologia). Museu Nacional da Universidade Federal do Rio de Janeiro.

MACHADO, Juliana. 2010. Espaços antropizados: entendendo os processos de reocupação de sítios arqueológicos a partir de uma visão etnoarqueológica. In: PEREIRA, Edith \& GUAPINDAIA, Vera. (Orgs.). Arqueologia Amazônica. Vol. 2. MPEG; IPHAN; SECULT, Belém. Pp.345-364.

MACHADO, Juliana. 2009. Arqueologia e História nas construções de Continuidade na Amazônia. Boletim do Museu Paraense Emílio Goeldi Vol. 41:57-70.

MARSHALL, Y e ALBERTI, B. 2014. A Matter of Difference: Karen Barad, Ontology and Archaeological Bodies. Cambridge Archaeological Journal vol 42(1): 19--36.

MAUÉS, R. H. 1997. A ilha encantada: medicina e xamanismo numa comunidade de pescadores. Belém: Novos Cadernos do NAEA.

MAUES, R.H. \& MOTTA-MAUES, M.A. 1978. O modelo da reima: representações alimentares de uma comida amazônica. Anuário Antropológico, vol. 77: 120-147. 
MENDES DOS SANTOS, Gilton. Da cultura à natureza: um estudo do cosmos e da ecologia dos Enawene-Nawe. Tese Doutorado em AntropologiaSocial - Universidade de São Paulo, São Paulo, 2006

MORAES, Claide. 2013 Amazônia ano 1000: Territorialidade, interação e conflito no tempo das chefias regionais. 2013. Tese (Doutorado) - Museu de Arqueologia e Etnologia, Universidade de São Paulo. São Paulo, 2013.

MORCATTY, T.Q. \& VALSECCHI, J. 2015. Social, biological, and environmental drivers of the hunting and trade of the endangered yellow-footed tortoise in the Amazon. Ecology and Society, 20(3).

MURRIETA, R.S.S. 2001. Dialética do Sabor: Alimentação, Ecologia e Vida Cotidiana em Comunidades Ribeirinhas da Ilha de Ituqui, Baixo Amazonas, Pará. Revista de Antropologia (USP), 44: 39-88.

NEVES, Eduardo. 2013. Sob o tempo dos equinócios: oito mil anos de história. Tese de livre docência. Museu de Arqueologia e Etnologia da Universidade de São Paulo, São Paulo.

NEVES, Eduardo e PETERSEN, James. 2005. Economy of Pre-Columbian Landscape Transformations in Central Amazonia. In: BALÉE, William e ERICKSON, Clark. (Orgs.). Time and Complexity in Historical Ecology: Studies in the Neotropical Lowlands. New York: Columbia University, v. 1: 279-310.

NUNGENT, S. 1993. Amazonian caboclo society: an essay on invisibility and peasant economy. Oxford: Berg.

PEZZUTI, J.C.B.; et al. 2004. A caça e a pesca no Parque Nacional do Jaú. In: Borges, S.H. (org.). Janelas para a biodiversidade no Parque Nacional do Jaú: uma estratégia para o estudo da biodiversidade na Amazônia. Fundação Vitória Amazônica, Manaus. p. 213-230.

PRADO, H.M.; FORLINE, L.C.; KIPNIS, R. 2012. As práticas de caça entre os Awá-Guajá: contribuições para uma análise de sustentabilidade de longo prazo em um contexto indígena AM. Boletim do Museu Paraense Emilio Goeldi: Ciencias Humanas, 7(2): 479-491.

POLITIS, Gustavo. 2007. Nukak: ethnoarchaeology of an Amazonian people. Left Coast Press.

QUEIROZ, Helder \& PERALTA, Nelissa. 2006. Reserva de Desenvolvimento Sustentável: manejo integrado dos recursos naturais e gestão participativa. In BECKER, B. e GARAY, I. (Orgs.). Dimensões humanas da biodiversidade. Vozes, Rio de Janeiro. Pp. 447-476.

REICHEL-DOLMATOFF, Gerardo. Cosmology as ecological analysis: A view from the rain forest. Man, Londres, n. 11, v. 3, p. 307-318, 1976.

REIS, Jose Alberione dos. 2017. Há uma condição de possibilidade de diálogo entre regimes de conversação e regimes de conhecimentos. Revista de Arqueologia, [S.l.], v. 30, n. 1, p. 120-143.

SANTOS, Rafael B. C. 2012. Passar para Índio: etnografia das emergências indígenas no médio Solimões. Relatório Final de Pesquisa CNPq/PCI. Inédito.

SCHAAN, Denise. The Camutins Chiefdom: Rise and Development of Social Complexity on Marajo Island, Brazilian Amazon, 2004. Ph.D. Dissertation - University of Pittsburgh, Department of Anthropology, 2004.

SCHAAN, Denise; RANZI, Alceu; PÄRSSINEN, Martti (Orgs.). Arqueologia da Amazônia Ocidental: os geoglifos do Acre. Belém: EditoraUniversitária UFPA, 2008. 192 p

SCHIFFER, M. B. 1987. Formation process of the archaeological record. Universityof New Mexico Press, Albuquerque.

SHEPARD JR, G.H.1999. Pharmacognosy and the Senses in Two Amazonian Societies. Tese (Doutorado em Antropologia) Dept. Anthropology, University of California, Berkeley.

SILVA, A.L. 2003. Uso de Recursos por populações ribeirinhas do Médio Rio Negro. Tese de Doutorado. Programa de Pós-Graduação em Ecologia da Universidade Estadual de São Paulo. São Paulo. 237p.

SILVA, Fabiola. 2000. As tecnologias e seus significados: Um estudo de caso a cerâmica do Xingu e da cestaria dos Kayapó-Xikrin sob uma perspectiva etonoarqueológica. Tese (Doutorado em antropologia). Universidade de São Paulo, São Paulo. 
UMA PERSPECTIVA ONTOLÓGICA PARA UMA ANÁLISE ETNOARQUEOLÓGICA DAS PAISAGENS DO LAGO AMANÃ, BAIXO JAPURÁ, AMAZONAS

SILVA, Fabiola. 2009. A etnoarqueologia na Amazônia: contribuições e perspectivas. Boletim do Museu Paraense Emílio Goeldi. Série Ciências da Terra, 4: 27-37

SILVA, Fabiola. 2013. Território, lugares e memória dos Asurini do Xingu. Revista de Arqueologia (Sociedade de Arqueologia Brasileira. Impresso), 26: 28-41.

SILVA, Fabiola. 2015. Arqueologia Colaborativa com os Asurini do Xingu: um relato sobre a pesquisa no igarapé Piranhaquara - Terra Indígena Koatinemo. Revista de Antropologia (São Paulo) , v. 58, p. 142-173.

SILVA, Fabiola \& GARCIA, Lorena. 2015. Território e memória dos Asurini do Xingu: Arqueologia Colaborativa na T.I. Kuatinemu, Pará. Amazônica, 7:74-99.

SILVA, Fabíola \& STUCHI, Francisco. 2010. Evidências e significados da mobilidade territorial: A Terra Indígena Kaiabi (Mato Grosso/Pará). Amazônica, 2: 46-70.

SMITH, N. 1996. The enchanted amazon rainforest: stories from a vanishing world. Gainsville: University Press of Florida.

STEPHENS, D.W.; Krebs, J.P. 1986. Foraging Theory. Princeton University Press, Princeton. 249p.

STEWART, A. M., D. KEITH e J. SCOTTIE. 2004. Caribou crossings and cultural meanings: placing traditional knowledge and archaeology in context in an Inuit landscape. Journal of Archaeological Method and Theory 11 (2): 183-212.

VASCONCELOS NETO, Carlos. 2016. Atividade caça na Reserva de Desenvolvimento Sustentável Amanã (RDSA): uma abordagem de ecologia histórica. 71 f. Dissertação (Mestrado em Ecologia). Instituto de Biociências da Universidade de São Paulo. São Paulo.

VALSECCH, João. 2012. Caça de Animais Silvestres nas Reservas De Desenvolvimento Sustentável Mamirauá e Amanã. Tese de Doutorado, Instituto de Ciências Biológicas. Universidade Federal de Minas Gerais.

VALSECCHI, J., AMARAL, P.V. 2009. Perfil da caça e dos caçadores na Reserva de Desenvolvimento Sustentável Amanã, Amazonas - Brasil. Uakari, 5(2): 33-48.

VASCONCELOS NETO, Carlos Frederico. 2016. Atividade de Caça em uma Comunidade da Reserva de Desenvolvimento Sustentável Amanã (RDSA). Dissertação de Mestrado. Instituto de Biociências da Universidade de São Paulo. 82 p.

VICKERS, W. 1989. Los Sionas y Secoyas: Su adaptación al ambiente amazónico. Quito: Ediciones Abya-Yala.

VIEIRA, Marina. 2013. Influências dos sistemas de manejo formal e informal na atividade de caça de subsistência na RDS Piagaçu-Purus, AM. Dissertação (Mestrado Ecologia), INPA, Manaus.

VIVEIROS DE CASTRO, Eduardo. 2002. A inconstância da Alma Selvagem e Outros Ensaios de Antropologia. Cosac \&Naify, São Paulo. 552 pp.

VIVEIROS DE CASTRO, Eduardo. 1996. Os pronomes cosmológicos e o perspectivismo ameríndio, MANA 2(2), $115-$

VIVEIROS DE CASTRO, Eduardo. 1987 [1979]. "A fabricação do corpo na sociedade xinguana". In: J. P. de Oliveira Filho (org.), Sociedades indígenas e indigenismo no Brasil. Rio de Janeiro: UFRJ/ Editora Marco Zero. pp. 31-39.

WAGLEY, C. 1988. Uma comunidade amazônica. Belo Horizonte: Itatiaia/Edusp.

WAWZYNIAK, João. 2012. Humanos e não humanos no universo transformacional dos ribeirinhos do rio Tapajós-Pará. Mediações - Revista de Ciências Sociais, v. 17

WAWZYNIAK, João. 2008. Assombro de Olhada de Bicho - Concepções de Saúde entre os Ribeirinhos do TapajósPará, Brasil. Tese (Doutorado em Antropologia) - Universidade Federal de São Carlos, 237 f.

WHITRIDGE, P. 2004. Landscapes, houses, bodies, things: place and the archaeology of Inuit imaginaries. Journal of Archaeological Method and Theory 11 (2): 213-50. 
JAQUELINE GOMES

ZEDEÑO, M. I. 1997. Landscapes, land use, and the history of territory formation: an example from puebloan southwest. Journal of Archaeological Method and Theory 4 (1): 63-103

ZEDEÑO, M. I. \& BROWSER, B. J. 2009. The archaeology of meaningful places, In B. J. BROWSER e M.I. ZEDEÑO (Eds), The archaeology of meaningful places. Salt Lake City. The University of Utah Press. pp. 1-14. 